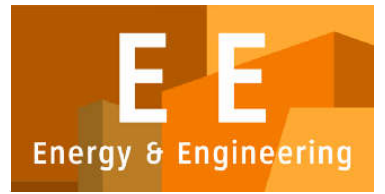

PAPER - OPEN ACCESS

\title{
Analisa Hambatan Produksi Pada Proses Assembling G Line Menggunakan Metode FMEA (Failure Mode and Effect Analysis) Di PT. XYZ)
}

\author{
Author : Poltak Nababan dan Kahalida Syahputri \\ DOI $\quad: 10.32734 /$ ee.v2i3.703 \\ Electronic ISSN : :2654-704X \\ Print ISSN : :2654-7031
}

Volume 2 Issue 3 - 2019 TALENTA Conference Series: Energy \& Engineering (EE)

This work is licensed under a Creative Commons Attribution-NoDerivatives 4.0 International License.

Published under licence by TALENTA Publisher, Universitas Sumatera Utara 


\title{
Analisa Hambatan Produksi Pada Proses Assembling G Line Menggunakan Metode FMEA (Failure Mode and Effect Analysis) Di PT. XYZ)
}

\author{
Poltak Nababan ${ }^{\mathrm{a}}$, Kahalida Syahputri ${ }^{\mathrm{b}}$ \\ ${ }^{a}$ Mahasiswa Teknik Industri, Fakultas Teknik, Universitas Sumatera Utara \\ ${ }^{b}$ Dosen Program Studi Teknik Industri, Fakultas Teknik, Universitas Sumatera Utara
}

khalidasyahputri@gmail.com,poltaknababan0608@gmail.com@gmail.com

\begin{abstract}
Abstrak
PT. XYZ adalah perusahaan yang bergerak dalam bidang industri manufaktur pembuatan kendaraan roda empat. Berdasarkan hasil observasi awal, diperoleh bahwa proses produksi pada bagian assembling $\mathrm{G}$ Line di perusahaan ini memiliki masalahmasalah yang dapat menghambat kelancaran proses produksi. Masalah-masalah yang terjadi pada saat proses produksi dapat mengurangi waktu kerja sehingga jumlah produk yang dihasilkan perusahaan menjadi berkurang. Masalah-masalah tersebut juga dapat mengakibatkan jumlah produk yang dihasilkan tidak sesuai dengan jumlah produk yang direncanakan. Untuk mengurangi hambatan produksi tersebut, penelitian ini menggunakan metode FMEA untuk mengidentifikasi penyebab yang paling potensial pada hambatan produksi pada proses assembling $\mathrm{G}$ line dan rekomendasi solusi yang diberikan. Berdasarkan penelitian yang dilakukan maka diketahui bahwa terdapat beberapa jenis hambatan produksi. Selanjutnya dilakukan perhitungan persentase kecacatan untuk memperoleh diagram pareto. Berdasarkan hasil perhitungan diperoleh bahwa jenis hambatan produksi yang dianalisis adalah final line no body dengan total hambatan 1400 dan persentase kecacatan 75,31\%. Rekomendasi solusi yang diberikan adalah dilakukannya pelatihan kepada operator agar operator memiliki skill yang lebih baik
\end{abstract}

Kata Kunci:Hambatan Produksi, Diagram Pareto, Cause and Effect Diagram, FMEA

\section{Abstract}

PT. XYZ is a company engaged in the manufacturing industry manufacturing four-wheeled vehicles. Based on the results of preliminary observations, it was found that the production process in the G Line assembling section in this company has problems that can hinder the smooth production process. The problems that occur during the production process can reduce work time so that the number of products produced by the company is reduced. These problems can also result in the number of products produced not in accordance with the number of products planned. To reduce these production bottlenecks, this study uses the FMEA method to identify the most potential causes of production bottlenecks in the $G$ line assembling process and the recommended solution given. Based on research conducted, it is known that there are several types of production barriers. Then the percentage of disability is calculated to obtain the Pareto diagram. Based on the calculation results obtained that the type of production constraints analyzed are the final line no body with a total resistance of 1400 and the percentage of disability $75.31 \%$. The recommended solution given is to conduct training for operators so that operators have better skills Keywords: Production Barriers, Pareto Diagrams, Cause and Effect Diagrams, FMEA 


\section{Pendahuluan}

PT. XYZ adalah perusahaan yang bergerak di bidang industri otomotif. Perusahaan ini berdiri pada tahun 1970. Plant II merupakan proyek baru khusus untuk kendaraan roda empat. Di sini dilakukan pressing, welding, painting, serta perakitan (assembling) kendaraan roda empat, dengan menggunakan berbagai peralatan teknologi tinggi dan merupakan yang terbesar di Asia Tenggara untuk saat ini.

Proses assembling adalah proses penggabungan unit body yang sudah dipainting dengan engine dan komponenkomponen lain, seperti roda, jok, dasboard, interior, dan komponen lainnya menjadi satu unit mobil. Proses ini meliputi proses trimming, chasis, dan final. Chasis adalah proses assembling pada bagian-bagian mobil yang berhubungan dengan chasis. Triming adalah proses assembling pada bagian atas mobil atau pemasangan interior dan eksterior mobil. Final adalah proses assembling untuk kelengkapan sesudah proses triming dan chasis seperti roda, bahan bakar, bumper, dan kelengkapan lainnya.

Proses assembling pada PT. XYZ memiliki masalah-masalah dalam prosesnya. Masalah-masalah yang terjadi pada saat proses produksi dapat mengurangi waktu kerja sehingga jumlah produk yang dihasilkan perusahaan menjadi berkurang. Masalah-masalah tersebut juga dapat membuat jumlah produk yang dihasilkan tidak sesuai dengan jumlah produk yang direncanakan.

Berdasarkan hal tersebut, maka peneliti ingin melakukan identifikasi tipe-tipe dan faktor-faktor penyebab dalam permasalahan assembling tersebut dengan menggunakan FMEA sehingga dapat memberikan rekomendasi solusi yang harus diperbaiki oleh perusahaan.

\section{Metodologi Penelitian}

Metode yang digunakan dalam penelitian ini adalah berupa observasi langsung di lapangan pada proses assembling $\mathrm{G}$ Line, disertai dengan wawancara terhadap kepala produksi. Adapun data sekunder yang dikumpulkan berupa data umum tentang perusahaan dan data historis hambatan produksi di PT. XYZ [1].

Penelitian ini mengidentifikasi penyebab yang paling potensial pada hambatan produksi pada proses assembling $G$ Line dengan menggunakan FMEA. FMEA adalah kependekan dari Failure Mode and Effect Analysis [2].

\subsection{Langkah-langkah Penelitian}

Langkah - langkah yang dilakukan dalam melakukan penelitian ini adalah sebagai berikut.

1. Studi Lapangan

Studi lapangan dilakukan untuk memperoleh informasi mengenai gambaran umum dan kondisi perusahaan yang sebenarnya.

2. Studi Pustaka

Studi pustaka dilakukan untuk memperoleh dan lebih memahami teori-teori yang berhubungan dengan pemecahan masalah. Sumber literatur berasal dari buku, jurnal, serta studi terhadap penelitian terdahulu dengan topik utama.

3. Rumusan Masalah

Berdasarkan studi pustaka dan studi lapangan, akan diketahui permasalahan yang ada sehingga dapat dirumuskan permasalahan yang sedang diteliti.

4. Penentuan Tujuan Penelitian

Penentuan tujuan penelitian digunakan untuk menjelaskan tujuan apa saja yang ingin dicapai dengan diadakannya penelitian.

5. Pengumpulan Data

Data yang dikumpulkan pada penelitian ini meliputi data primer dan data sekunder yaitu:
a. Data gambaran umum perusahaan
b. Data struktur organisasi
c. Data jumlah pekerja saat ini
d. Data job description tiap pekerja
e. Data hambatan produksi. 
6. Pengolahan Data

Pengolahan data yang dilakukan dalam penelitian ini, yaitu:

a. Menghitung persentase hambatan produksi dan penggambaran diagram pareto.

b. Menentukan faktor-faktor yang berpengaruh secara signifikan terhadap hambatan produksi.

c. Menghitung nilai Risk Priority Number (RPN).

d.Memberikan rekomendasi solusi.

7. Analisis dan Kesimpulan

Analisis dan kesimpulan yang dilakukan dalam penelitian ini, yaitu:

a.Menganalisis besarnya persentase hambatan produksi.

b.Menganalisis faktor-faktor yang berpengaruh secara signifikan terhadap hambatan produksi.

c.Menarik kesimpulan yang merupakan ringkasan akhir yang mampu menjawab rumusan penelitian yang dilakukan serta memberikan saran penelitian.

\section{Hasil dan Pembahasan}

\subsection{Diagram Pareto}

Diagram Pareto dibuat untuk menemukan atau mengetahui masalah atau penyebab yang merupakan kunci dalam penyelesaian masalah dan perbandingan terhadap keseluruhan [3]. Dengan mengetahui penyebab-penyebab yang dominan, dapat ditetapkan prioritas perbaikan. Perbaikan pada faktor penyebab yang dominan ini akan membawa pengaruh yang lebih besar dibandingkan dengan penyelesaian penyebab yang tidak berarti [4].

Langkah-langkah pembuatan Pareto Diagram adalah sebagai berikut:

1. Kumpulkan data dan susun data berdasarkan jumlah yang paling besar ke yang paling kecil/tentukan jumlah kumulatifnya.

2. Gambar grafik dengan sumbu-Y sebagai jumlah data dan sumbu-X sebagai kategori data dan digambar dengan skala tepat.

3. Gambarkan diagram batang pada sumbu-X sesuai kategori data dan jumlahkan mulai dari jumlah data terbesar hingga yang terkecil.

4. Dengan menggunakan tabel kumulatif gambar grafik kumulatifnya.

Pareto yang digunakan pada pemecahan masalah ini yaitu menggunakan pareto $70 \%-30 \%$. Berdasarkan aturan pareto $70 \%-30 \%$, permasalahan yang memiliki persentase kumulatif lebih dari atau sama dengan $70 \%$ yang harus dianalisis lebih lanjut. Berdasarkan hasil yang diperoleh, maka hambatan yang akan dianalisis lebih lanjut adalah final line no body karena memiliki persentase kumulatif sebesar 75,31\% .

\subsection{Cause and Effect Diagram}

Diagram ini dikenal dengan istilah diagram tulang ikan (fish bone diagram) yang diperkenalkan pertama kalinya oleh Prof. Kaoru Ishikawa (Tokyo University) pada tahun 1943 [5]. Diagram ini berguna untuk menganalisis dan menemukan faktor-faktor yang berpengaruh secara signifikan di dalam menentukan karakteristik kualitas output kerja [6]. Di samping itu juga diagram ini berguna untuk mencari penyebabpenyebab yang sesungguhnya dari suatu masalah. Dalam hal ini metode sumbang saran (brainstorming method) akan cukup efektif digunakan untuk mencari faktor-faktor penyebab terjadinya penyimpangan kerja secara detail.

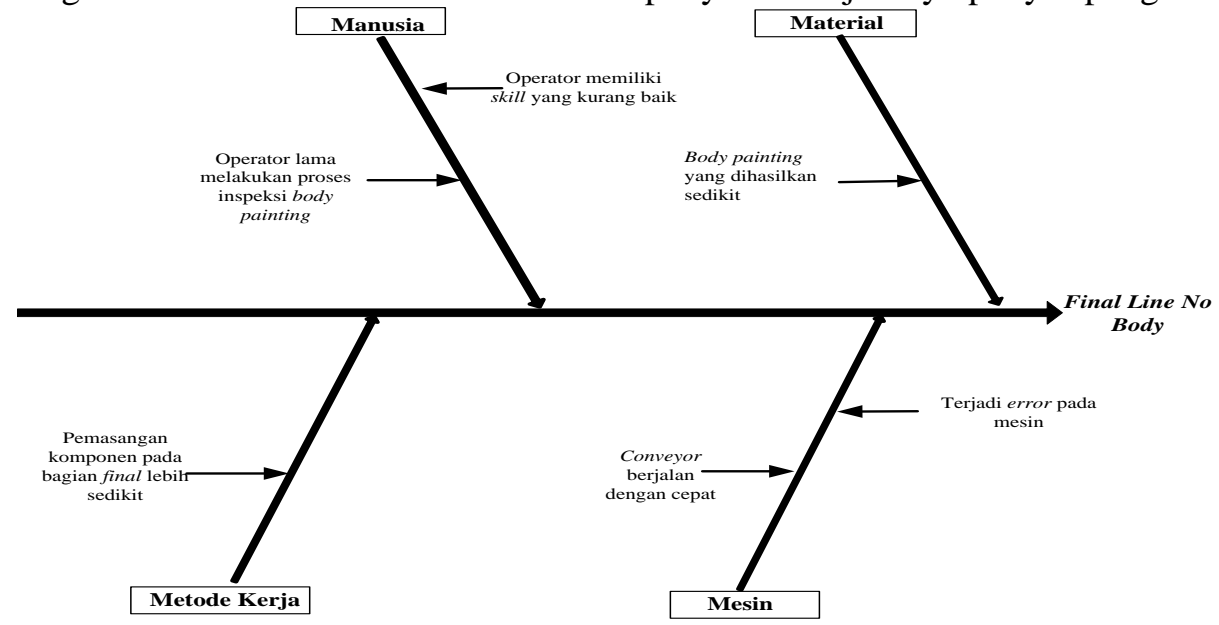




\subsection{Failure Mode Effect Analysis (FMEA)}

FMEA adalah metode untuk mengidentifikasi dan menganalisa potensi kegagalan dan akibatnya yang bertujuan untuk merencanakan proses produksi secara baik dan dapat menghindari kegagalan proses produksi dan kerugian yang tidak diinginkan

Tabel 1. Perhitungan Nilai Risk Priority Number (RPN)

\begin{tabular}{|c|c|c|c|c|c|c|}
\hline $\begin{array}{c}\text { Kategori } \\
\text { Penyebab } \\
\text { Hambatan }\end{array}$ & $\begin{array}{l}\text { Seve } \\
\text { rity }\end{array}$ & Faktor yang Mempengaruhi & $\begin{array}{l}\text { Occu } \\
\text { rence }\end{array}$ & Proses Kontrol Saat Ini & $\begin{array}{l}\text { Dete } \\
\text { ction }\end{array}$ & RPN \\
\hline \multirow{2}{*}{ Manusia } & \multirow[b]{2}{*}{7} & $\begin{array}{l}\text { Operator lama melakukan } \\
\text { proses inspeksi body painting }\end{array}$ & 7 & Pengawasan dilakukan secara visual & 4 & 196 \\
\hline & & $\begin{array}{l}\text { Operator memiliki skill yang } \\
\text { kurang baik }\end{array}$ & 7 & Pengawasan dilakukan secara visual & 7 & 343 \\
\hline \multirow[b]{2}{*}{ Mesin } & \multirow[b]{2}{*}{5} & Terjadi error pada mesin & 8 & Dilakukan perbaikan mesin & 6 & 240 \\
\hline & & $\begin{array}{l}\text { Conveyor berjalan dengan } \\
\text { cepat }\end{array}$ & 9 & Pengawasan dilakukan secara visual & 5 & 225 \\
\hline Material & 5 & $\begin{array}{l}\text { Body painting yang dihasilkan } \\
\text { sedikit }\end{array}$ & 9 & $\begin{array}{l}\text { Pengawasan terhadap } \\
\text { operator }\end{array}$ & 7 & 315 \\
\hline $\begin{array}{l}\text { Metode } \\
\text { Kerja }\end{array}$ & 7 & $\begin{array}{l}\text { Pemasangan komponen pada } \\
\text { bagian final lebih sedikit }\end{array}$ & 9 & $\begin{array}{l}\text { Pengawasan terhadap kinerja } \\
\text { operator }\end{array}$ & 4 & 252 \\
\hline
\end{tabular}

Berdasarkan perhitungan RPN diatas, diperoleh bahwa prioritas utama perbaikan pada PT. XYZ ialah lebih memperhatikan skill yang dimiliki oleh operator khususnya operator baru agar dapat menghasilkan body painting yang baik. Rekomendasi yang diberikan untuk permasalahan ini adalah dilakukan pelatihan kepada operator sehingga operator memiliki skill yang lebih baik.

\section{Kesimpulan}

Kesimpulan yang diperoleh dari pembahasan diatas adalah sebagai berikut.

1. Jenis hambatan produksi yang terjadi pada proses assembling pada PT. XYZ adalah final line no body, lifter suspension error, pbs atas error, pokayoke error, $\mathrm{dl}$-1 error, masalah pengiriman part, repair in line / tarik andon, masalah pemesanan part, dl -2 error, proses sub assy lambat, hoist error, conveyor/hanger, masalah welding, rear axle lifter error, mesin power steering filling error, body miring, $\mathrm{dl}-4$ error, dan mesin press knuckle rusak.

2. Berdasarkan hambatan-hambatan pada poin di atas, jenis hambatan yang paling banyak terjadi adalah final line no body yaitu sebanyak 1400 dengan persentasi sebesar $75,31 \%$.

3. Masalah Final line no body disebabkan oleh operator memiliki skill yang kurang baik.

4. Rekomendasi solusi terhadap faktor penyebab hambatan tersebut adalah dilakukan pelatihan kepada operator sehingga operator memiliki skill yang lebih baik.

\section{Referensi}

[1] Ginting, Rosnani. 2007. Sistem Produksi Cet I. Yogyakarta: Graha Ilmu.

[2] Hanif, Richma Yulinda, dkk. 2015. Perbaikan Kualitas Produk Keraton Luxury di PT. X dengan Menggunakan Metode Failure Mode and Effect Analysis (FMEA) dan Fault Tree Analysis (FTA)

[3] McDermot, Robin E. 2009. The Basic of FMEA. Edisi 2. USA : CRC Press

[4] Rusmana, Faisal Waisul Kurni dan Syarif Hidayat. 2017. Analisis Hambatan dan Rekomendasi Solusi pada Proses Outbound Logistic PT. XYZ dengan Seven Tools dan FMEA. Seminar Nasional Inovasi Dan Aplikasi Teknologi Di Industri 2017, ITN Malang.

[5] Supono, Joko dan Lestari. 2018. Analisis Penyebab Kecacatan Produk Sepatu Terrex AX2 Goretex dengan Menggunakan Metode Fault Tree Analysis (FTA) dan Failure Mode and Effect Analysis (FMEA) di PT. Panarub Industri. Journal Industrial Manufacturing Vol. 3, No. 1, Januari 2018, pp. 15-22.

[6] Tanjong, Santoni Darmawan. 2003. Implementasi Pengendalian Kualitas dengan Metode Statistik pada Pabrik Spareparts CV Victory Metallurgy Sidoarjo. Jurnal Ilmiah Mahasiswa Universitas Surabaya Vol.2 No.1 (2013) 